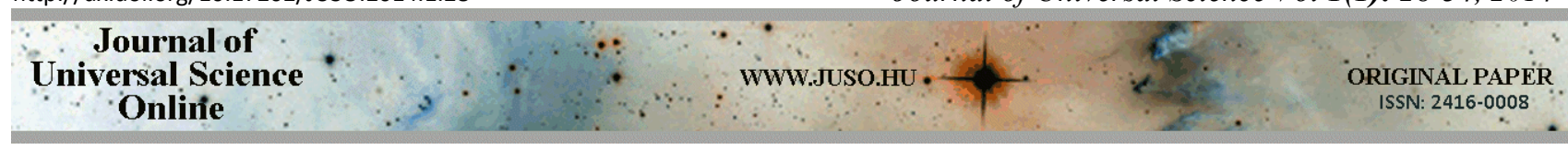

\title{
Growth inhibitory effects of bioactive metabolites in wood extracts of Robinia pseudoacacia L. inhibit the growth of various microorganisms
}

\section{Szandra DOBRÁNYI ${ }^{1}$, Gábor DANCS ${ }^{1}$, Katalin POSTA ${ }^{2}$ and László FÜLÖP ${ }^{1, *}$}

\author{
${ }^{1}$ Szent István University, Faculty of Agriculture and Environmental Sciences, \\ Department of Chemistry and Biochemistry \\ ${ }^{2}$ Szent István University, Plant Protection Institute, Microbiological and Environmental Toxicology Group \\ *Corresponding Author; e-mail: Fulop.Laszlo@mkk.szie.hu
}

Received: 22 October 2014 / Revised: 29 November 2014 / Accepted: 19 December 2014

Keywords: Robinia pseudoacacia, wood, inhibition, metabolites

\begin{abstract}
The need for more efficient use of natural resources recently became apparent. Lowering the amount of harmful chemicals released into the environment is a crucial task. Besides it is essential to seek for novel resources closer to natural origin.

The aggressive growth of certain plant species is attributed to their metabolic features as well. Several plant secondary metabolites have been identified recently that are crucial for their intensive spread. These metabolites are only present in particular taxonomic groups. The most important attribute they share is that they regulate the interactions between the plant and the environment. These metabolites often possess traits that inhibit the growth of pathogen microbes. Due to their antimicrobial effects these bioactive substances may be utilized as novel pesticide agents in the future.

In our project we assessed the inhibitory effects of various black locust (Robinia pseudoacacia L.) wood extracts on the growth of different microorganisms using agar plate disc diffusion method. Our results suggest that black locust wood extracts evolves comprehensive inhibition against both gram-negative and gram-positive bacteria and Fusarium proliferatum The highest bioactivity was carried by the hexane and methanolic fraction. Further purification using HPLC revealed some particular components that show significant correlation with the inhibitory effects of the extracts. Some extracts were able to lower the infection ability of Fusarium proliferatum in in-vivo infection tests.
\end{abstract}

\section{Introduction}

Pathogens may cause severe damages in crop production and in animal husbandry in this way they are responsible for remarkable economic losses. The metabolic system of aggressively spreading plants may involve substances that can be used as active agents of novel pesticides, antimicrobial pharmaceuticals and disinfectants. Recently intensive research has begun to discover elements of the secondary metabolic system of different plant species. There are several types of secondary metabolites that play substantial role in the natural defense systems of particular plants and these compounds are of great interest. The natural processes give the basis of our research for instance phenolic compounds often have role in defense system of plants against insects [5] and they often 


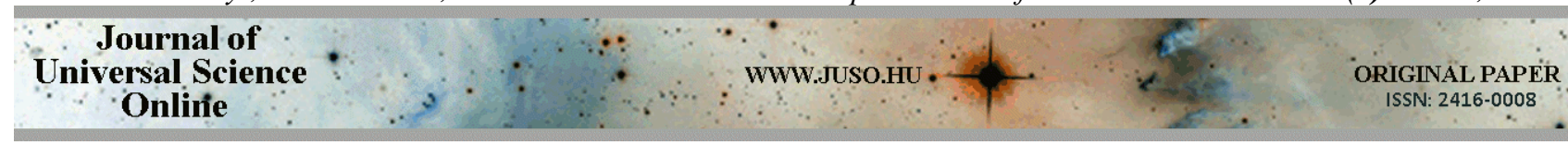

possess inhibitory attributes against microorganisms [1]. The group of flavonoids is sufficiently promising [4]. Furthermore several types of small-sized peptides often participate in the complex defense system of plants [2].

Black locust timber is known to be durable and resistant to decay processes that is due to the chemical constituents of wood as well. The decay resistance is ,extractable" and can be transmitted to susceptible wood [11]. Also the vigorous regeneration of the living tree gave the basis for the extensive chemical analysis of black locust extracts from wood and bark [10,11]. Plants often produce high amounts of secondary metabolites that are responsible for the control of ecological interactions and thus they play important role in determining the directions of natural selection in communities, for example allelopathy is a phenomenon accomplished by secondary metabolites. Secondary metabolites raised industries' attention hunting for new

\section{Material and methods}

We gained crude extracts from black locust wood and bark using different solvents like aqueous ethanol (50\%), aqueous methanol (50\%), phosphate buffer and hexane $[3,7,11,13,14$,$] . We applied the pour plate$ paper disk diffusion method biotest for assessing the inhibition effect of the extracts on the growth of microbes that include plant pathogen fungi and various bacteria [2]. Paralelly we conducted the fractionation of the crude plant extracts using reverse-phase HPLC. We also applied in vivo infection test in the case of Fusarium proliferatum treated with black locust extracts, to detect whether the treatment had any effect on infection ability of the pathogen. In case of black locust still several elements are to be identified and evaluated. Our goal was to analyze black

\section{Extraction}

We used freshly collected black locust woody stem to gain extracts according to several and more sustainable resources of chemicals. According to recent studies several parts of Robinia pseudoacacia L. contains bioactive metabolites $[8,12,14]$. These substances may have the potential to become new resources of chemical agents like pesticides, antimicrobial pharmaceuticals, disinfectants and herbicides. Black locust leaves, bark and heartwood contains significant amount of phenolic compounds, especially flavonoids, this group of metabolites is considered to have important role in bioactivity $[6,10,13]$. This complex system of secondary metabolites need to be examined extensively.

Our project aimed to found the basis for utilizing the metabolic features of the aggressively growing tree, black locust (Robinia pseudoacacia L). The basic hypothesis of our research was that these metabolites are extractable and may be used in in vitro bioassays to evaluate their efficiency against several microorganisms.

locust extractives gained by various methods $[3,6,11,13]$ including solvents like $50 \%$ methanol in water, hexane to separate lipophilic fraction, and phosphate buffer to preserve the active peptides. We applied agar plate paper disc diffusion method [9] to evaluate the inhibitory effect of extracts on the growth of four microbes: Fusarium proliferatum, a fungal plant pathogen, Micrococcus luteus and Staphylococcus aureus, two Gram-positive bacteria and Escherichia coli, a Gram-negative bacterium. We also applied in vivo infection test in the case of Fusarium proliferatum treated with black locust extracts, to detect whether the treatment had any effect on infection ability of the pathogen. We conducted parallel measurements using RP-HPLC [14].

methods [8,11,13]. We applied $50 \mathrm{v} / \mathrm{v} \%$ solution of ethanol and methanol, hexane and 


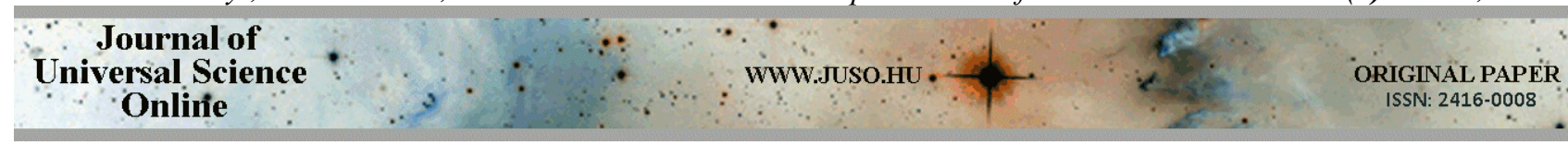

phosphate buffer as solvents. We added $3 \mathrm{~g}$ of black locust timber powdered with liquid nitrogen to $30 \mathrm{ml}$ solvent. after 2 minutes of sonication we extracted the timber at $4^{\circ} \mathrm{C}$

\section{Growth tests}

We used Agar plate paper disc diffusion method [9] to asses the growth inhibitory effects of the extracts in case of four microbe species, that are the following: Fusarium proliferatum, Micrococcus luteus, Staphylococcus aureus and Escherichia coli. We removed alcoholic solvents with a rotary vaccum evaporator and hexane with sterile air flow. We made suspensions from fresh 24 hour microbe cultures with sterile distilled water and spread $100 \mu 1$ on agar plates. We applied Martin agar plates in case of

\section{Infection tests}

We performed infection tests in case of Fusarium proliferatum treated with black locust extracts. The Capsicum annuum fruits were washed with sterile distilled water then we placed them into sterile tissue culture boxes and $1 \times 1 \times 0,5 \mathrm{~cm}$ agar cubes were placed into the boxes which were cut directly from the growth tests. We used Fusarium proliferatum agar plates as infection source treated with the methanolic and phosphate

\section{HPLC tests}

Paralelly we conducted RP-HPLC tests according to the method of Zhang et al., 2008, we used $\mathrm{C}_{18}$ coloumn with the following solutions: A: distilled water $0,1 \%$ ammonium acetate, and B: $80 \%$ acetonitrile $0,1 \%$

\section{Results and discussions}

\section{Biotests}

Our results are summarized on Fig.1. sizes of growth inhibition zones are in $\mathrm{mm}$. The values are the result of three independent extractions and five parallel repetitions in case of each extracts. The values are corrected with the correspondent methods' control values. overnight on shaker. We also used phase separation based on solubility differences in case of metahnolic extraction and watermethanol residues of hexane esxtractions.

Fusarium proliferatum and Nutrient agar plates in case of bacteria. Then we placed the paper discs soaked in fershly filtered extracts with sterile tweezers, we used sterile syringe filters (VWR, PES, $0,2 \mu \mathrm{m}$ ) and paper discs of $5 \mathrm{~mm}$ diameter. Our negative controll was sterile distilled water and we used a surface disinfectant Mikrozid Liquid (etanol, propanol, glutáraldehid, etilhexanal) as positive controll. We documented the size of the developing inhibition zones daily on the first week and weekly afterwards.

buffer extracts, untreated and the correspondent method control treatment agar plates were tested as well. We documented the visible alterations for four weeks every other day. Infected Capsicum annuum fruits were tested for Fusarium proliferatum by starting new cultures on fresh Martin agar plates as a control, we got Fusarium proliferatum cultures as result in all cases.

ammonium acetate, with $40 \mathrm{~min}$ gradient from $0 \% \mathrm{~B}$ to $100 \% \mathrm{~B}$. The chromatograms were evaluated at $215,280,325$ and $510 \mathrm{~nm}$ wavelenghts.

We also took into consideration the permanence of growth inhibition. Methanolic and phosphate buffer extracts proved to be the most effcetive against all microbe species. Hexane extracts also showed significant bioactivity Staphylococcus aureus 

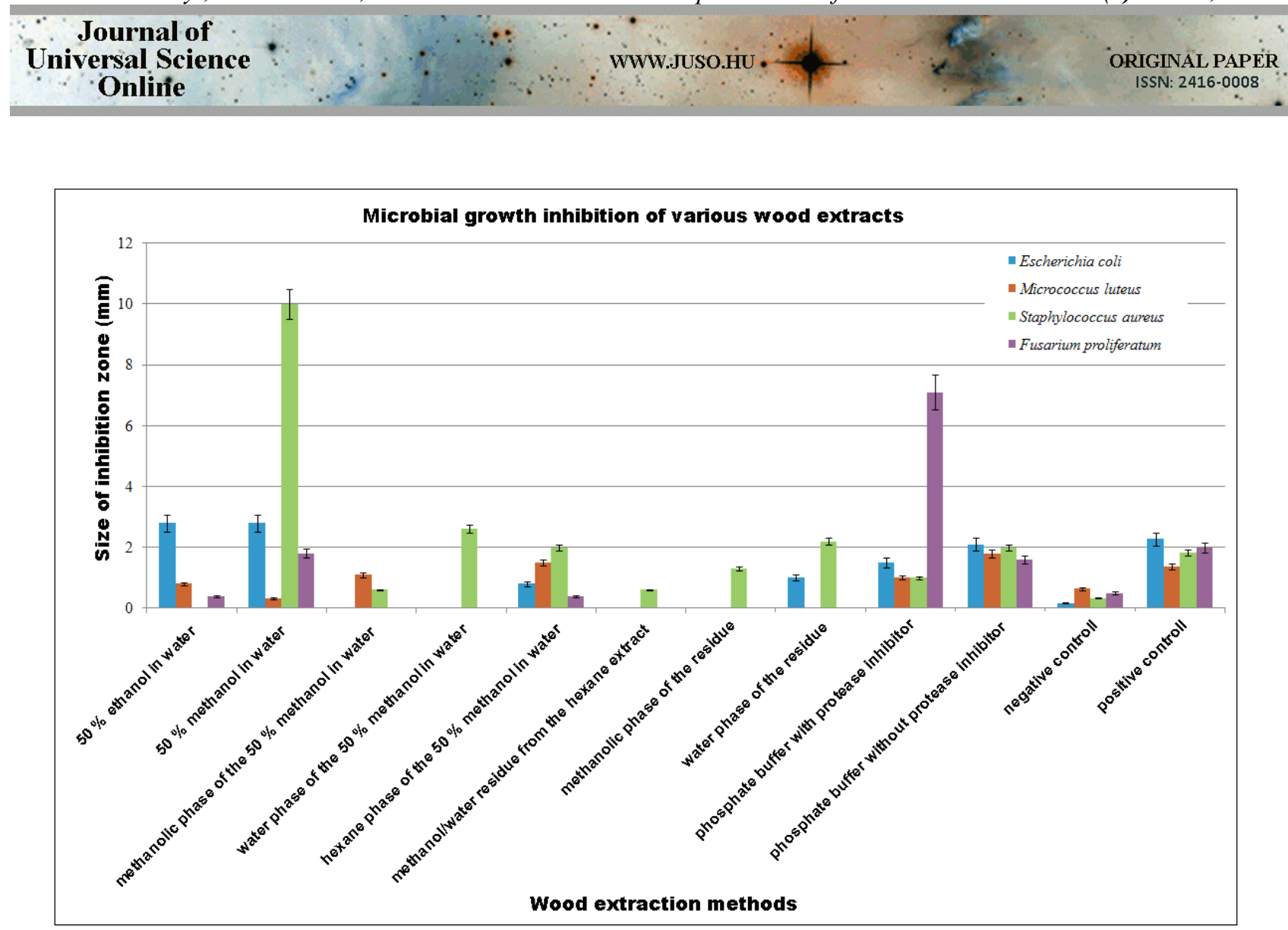

Fig. 1. Rates of growth inhibition

showed the most susceptibility to treatments with black locust wood extracts. According to the resukts of biotests with various phases of the extracts the most bioactivity were carried by the organic phase, water phase only showed little activity. Values represent the results of three different extractions and five parallel repeats of each extract.

\begin{tabular}{|c|c|c|c|c|}
\hline Extraction methods & $\begin{array}{c}\text { Escherichia } \\
\text { coli }\end{array}$ & $\begin{array}{c}\text { Micrococcu } \\
\text { luteus }\end{array}$ & $\begin{array}{c}\text { Staphylococcus } \\
\text { aureus }\end{array}$ & $\begin{array}{c}\text { Fusarium } \\
\text { proliferatum }\end{array}$ \\
\hline $50 \%$ ethanol in water extract & 2,8 & 0,8 & 0 & 0,4 \\
\hline $50 \%$ methanol in water extract & 2,8 & 0,32 & 10 & 1,8 \\
\hline $\begin{array}{l}\text { Methanolic phase of the } 50 \% \text { methanol in } \\
\text { water extract }\end{array}$ & 0 & 1,1 & 0,6 & 0 \\
\hline $\begin{array}{l}\text { Water phase of the } 50 \% \text { methanol in water } \\
\text { extract }\end{array}$ & 0 & 0 & 2,6 & 0 \\
\hline $\begin{array}{l}\text { Hexane phase of the } 50 \% \text { Methanol in water } \\
\text { extract }\end{array}$ & 0,8 & 1,5 & 2 & 0,4 \\
\hline $\begin{array}{l}\text { Methanol/water residue from the hexane } \\
\text { extraction }\end{array}$ & 0 & 0 & 0,6 & 0 \\
\hline Methanolic phase of the residue & 0 & 0 & 1,3 & 0 \\
\hline Water phase of the residue & 1 & 0 & 2,2 & 0 \\
\hline $\begin{array}{l}\text { Phosphate buffer with protease inhibitor } \\
\text { complex }\end{array}$ & 1,5 & 1 & 1 & 7,1 \\
\hline $\begin{array}{l}\text { Phosphate buffer without protease inhibitor } \\
\text { complex }\end{array}$ & 2,1 & 1,8 & 2 & 1,6 \\
\hline Negative control & 0,2 & 0,6 & 0,3 & 0,5 \\
\hline Positive control & 2,3 & 1,4 & 1,8 & 2,0 \\
\hline
\end{tabular}

Table 1. Rates of growth inhibition caused by wood extracts.

Values represent the size of inhibition zone around the paper discs. 


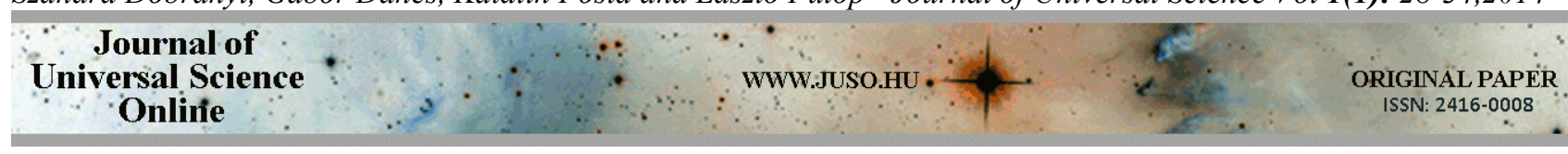

Data are already corrected with the particular control values of each method. Alcoholic solvents and hexane were removed from the extracts before the biotests using rotary

\section{Infection tests}

Control Fusarium caused intensive rot even two weeks after the infection, on the 4 . week the fruit suffered severe decay (Fig.2.). evaporator or air flow. Extracts were sterilized using sterile syringe filters before biotests.

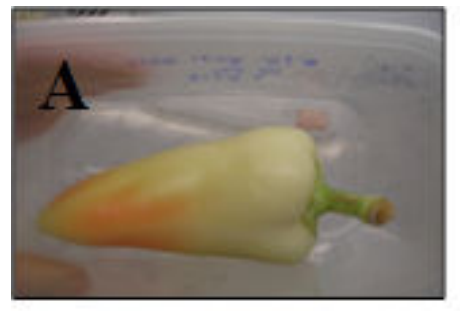

Within two weeks the Fusarium treated with phosphate buffer did not cause rot symptoms.
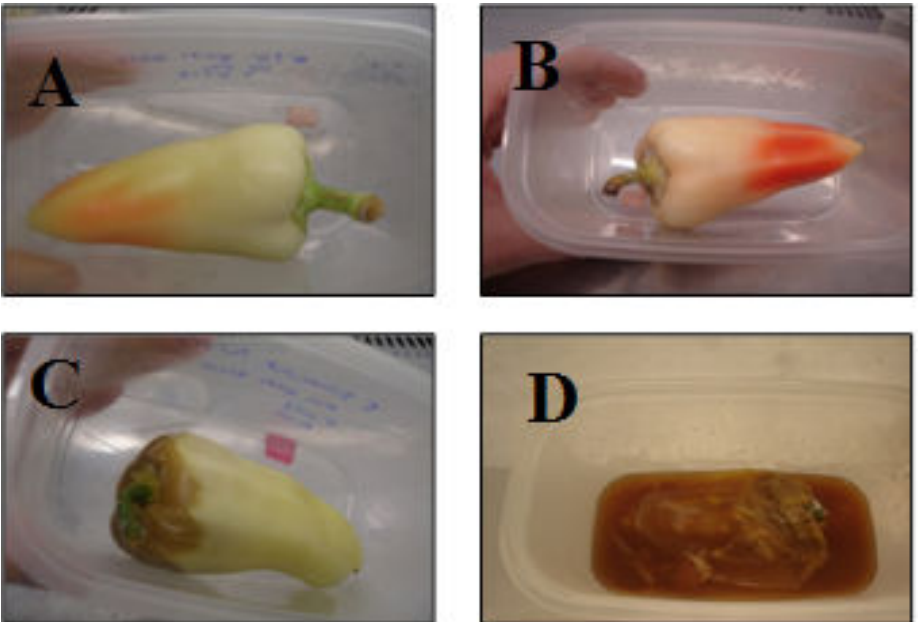

Fig. 2. Results of in vivo infection tests Fusarium proliferatum treated with phosphate buffer extracts of black locust wood showed reduced ability to infect Capsicum annuum fruits two (A) and four weeks (B) after infection compared to control two (C) and four weeks (D) after infection. We applied three parallel repeats.

Four weeks after the infection the paprika fruits infected from the inhibited zone showed much less severe symptoms of decay than the fruits infected with non-inhibited control fungi. However the agar cube cut from the same agar plate but from the non-inhibited growth zone caused severe rot on the paprika fruits.

\section{$H P L C$}

Cromatogram patterns from HPLC tests were confronted with the inhibition values of the extracts.

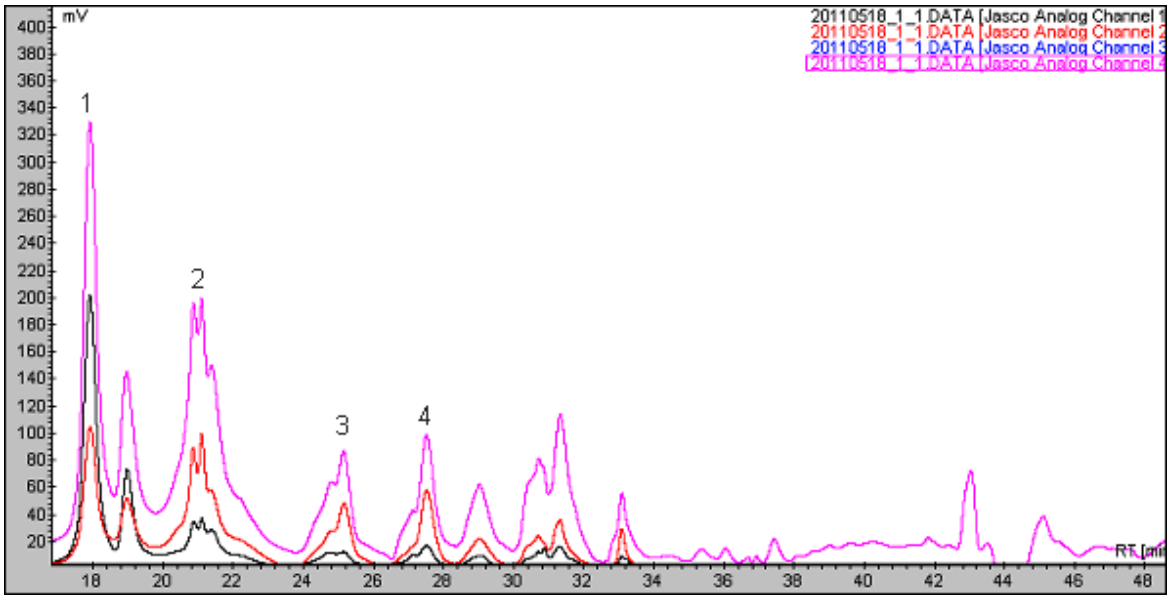

Fig. 3. Chromatogram of a methanolic wood extract.

(purple $-215 \mathrm{~nm}$, blue $-280 \mathrm{~nm}$, black $-325 \mathrm{~nm}$, red $-510 \mathrm{~nm}$ ) 


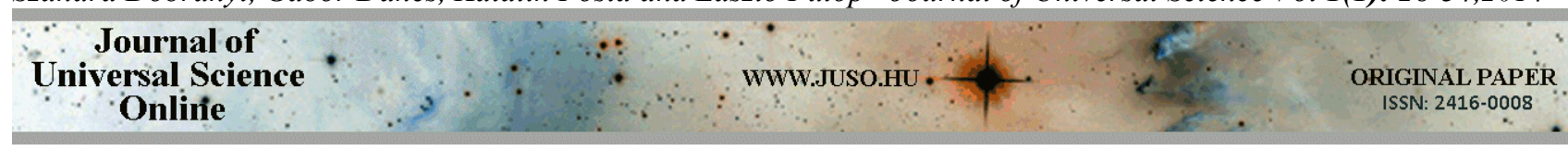

Correlation analysis results show four peaks that may be in correspondence with the growth inhibition shown by the particular extracts.

\begin{tabular}{|c|c|c|c|}
\hline $\begin{array}{c}\text { Peak } \\
\text { No. }\end{array}$ & $\begin{array}{c}\text { Escherichia } \\
\text { coli }\end{array}$ & $\begin{array}{c}\text { Micrococcus } \\
\text { luteus }\end{array}$ & $\begin{array}{c}\text { Staphylococcus } \\
\text { aureus }\end{array}$ \\
\hline $\mathbf{1 .}$ & 0,67 & 0,60 & 0,11 \\
\hline $\mathbf{2 .}$ & 0,77 & 0,49 & 0,05 \\
\hline $\mathbf{3 .}$ & 0,61 & $-0,20$ & 0,56 \\
\hline $\mathbf{4 .}$ & 0,66 & $-0,35$ & 0,65 \\
\hline
\end{tabular}

Table. 2. Correlation analysis of microbial growth inhibition rates and four particular peaks of the HPLC results. The blue colour indicated the positive correlation of test.

Fractions of the resulting peaks were collected so that we can test the fractions

\section{Conclusions}

The most intensive bioactivity were shown by the methanolic and phosphate buffer and hexane extratxs of black locust wood. Our results are in correspondence with detailed by literature however we could not find significant effects showed by the water phase. It is important to mention that we applied metahnolic extraction for the first time in case of black locust. In case of phase separation bioactivity is carried mostly by the organic phase. Besides it is an important result that lipophilic pahse was effective against all microbe species. Out of the four microbe

\section{References}

1. Castillo F, Hernández D, Gallegosa G, Mendez M, Rodríguez R, Reyes A, Aguilar C N (2010): In vitro antifungal activity of plant extracts obtained with alternative organic solvents against Rhizoctonia solani. Industrial Crops and Products 32 (3), 324-328

2. Castro MS and Fontes W (2005): Plant Defense and Antimicrobial Peptides. Protein and Peptide Letters $12(1), 11-16$

3. Claudot AC, Ernst D, Sandermann Jr H, Drouet A (1999): Cloning and characterization of two members of the chalcone synthase gene family from walnut. Plant Physiol. Biochem 37 (10), 721-730 corresponding to the particular peaks in our biotest system.(Table 2.) species Staphylococcus aureus shows the most susceptibility to black locust wood extracts. The effectiveness of phosphate buffer extarcts are important as this method is capable of direct extraction of biologically active agents.

An importatnt result of HPLC separation is that we could identify four peaks that can be related to the showed growth inhibition. In our further work we would like to test these fractions separately then the identification of substances will be our most important task.

4. Cushine TPT and Lamb AJ (2005): Antimicrobial activity of flavonoids. International Journal of Antimicrobial Agents 26, 343-356

5. Dübeler A, Voltmer G, Gora V, Lunderstadt J, Zeeck A (1997): Phenols from Fagus sylvatica and their role in defence against Cryptococcus fagisuga. Phytochemistry 45 (1), 51-57

6. Dünisch O, Richter HG, Koch G (2009): Wood properties of juvenile and mature heartwood in Robinia pseudoacacia L. Wood Sci Technol 44 (2), 301-313 


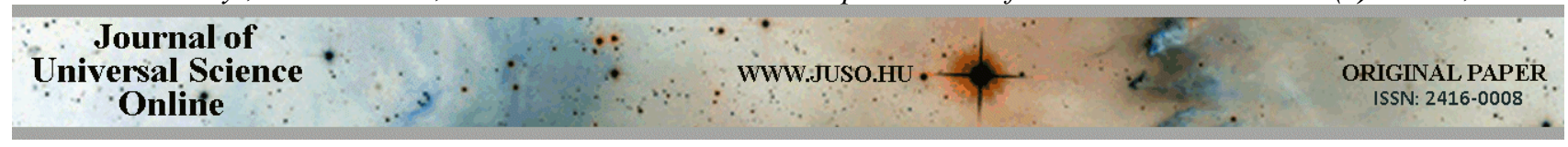

7. Monsálvez M, Zapata N, Vargas M, Berti M, Bettner M, Hernández V (2010): Antifungal effects of nhexane extract and essential oil of Drimys winteri bark against take-all disease. Industrial crops and products 31 (2), 239-244

8. Nasir H, Iqbal Z, Hiradate S, Fujii Y(2005):

Allelopathic potential of Robinia pseudoacacia L. J of Chem Ecol 31 (9), 2179-2192

9. Othman M, San Loh H, Wiart C, Khoo TJ, Lim KH, Ting KN (2011): Optimal methods for evaluating antimicrobial activities from plant extracts. J of Microbiol Methods 84 (2), 161-166

10. Putman LJ, Laks PE, Pruner MS (1989): Chemical Constituents of Black Locust Bark and their Biocidal Activity. Holzforschung 43 (4), 219-224
11. Smith AL, Campbell CL, Walker DB, Hanover JW (1989): Extracts from Black Locust as Wood Preservatives: Extraction of Decay Resistance from Black Locust Heartwood. Holzforschung 43 (5), 293296

12. Talas-Ogras T, Ipekci Z, Bajrovic K, Gözükirmizi N (2005): Antibacterial activity of seed proteins of Robinia pseudoacacia. Fitoterapia 76 (1), 67-72

13. Veitch NC, Elliot PC, Kite GC, Lewis Gp (2009): Flavonoid glycosides of the black locust tree, Robinia pseudoacacia (Leguminosae). Phytochemistry 71 (4), 479-486

14. Zhang ZY, Dai GH, Zhuge YY, Li YB (2008): Protective effect of Robinia pseudoacacia Linn1 extracts against cucumber powdery mildew fungus, Sphaerotheca fuliginea. Crop protection 27 (6), 920925 